\title{
Iron Assimilation and Carbon Metabolism in 'Concord' Grapevines Grown at Different pHs
}

\author{
Brandon R. Smith ${ }^{1}$ and Lailiang Cheng ${ }^{2}$ \\ Department of Horticulture, Cornell University, 134A Plant Science, Tower Road, Ithaca, NY 14853
}

\begin{abstract}
Additional INDEX words. Aconitase, active Fe, chlorosis, citrate, Fe inefficiency, ferric chelate reductase, fructose-6phosphate, glucose-6-phosphate dehydrogenase, malate dehydrogenase, NAD(P)-isocitrate dehydrogenase, NAD(P)-malic enzyme, phosphoenolpyruvate (PEP) carboxylase, PEP phosphatase, 3-phosphoglycerate, pyruvate kinase, Vitis labruscana, xylem sap $\mathrm{pH}$, lime-induced chlorosis
\end{abstract}

\begin{abstract}
Concord' grapevines (Vitis labruscana Bailey) are susceptible to lime-induced chlorosis, which decreases growth and productivity. In two separate experiments, we grew own-rooted vines in a peat-perlite medium adjusted to different $\mathrm{pHs}$ with $\mathrm{CaCO}_{3}$ to characterize how lime-induced $\mathrm{Fe}$ deficiency affects root and leaf ferric chelate reductase (FCR) and key enzymes and metabolites involved with glycolysis and the tricarboxylic acid (TCA) cycle in leaves. In addition, we measured the $\mathrm{pH}$ of the xylem sap as well as Fe, citrate, and malate concentrations. For both experiments, foliar levels of total $\mathrm{Fe}$, active $\mathrm{Fe}$ (extracted in $0.1 \mathrm{~N} \mathrm{HCl}$ ), and chlorophyll decreased as lime rate increased. An increase in root-medium $\mathrm{pH}$ from 5.8 to 7.5 resulted in a 10-fold increase in root FCR activity, whereas leaf FCR activity decreased 10-fold. An increase in root-medium $\mathrm{pH}$ did not raise xylem sap pH but decreased Fe and citrate to some extent. Xylem malate was highest at pH 6.6 and decreased both above and below this pH. Foliar data were evaluated in relation to active Fe content, because it is a better indicator of Fe nutritional status. Lower active Fe decreased midday $\mathrm{CO}_{2}$ assimilation and PSII quantum efficiency as well as night respiration. As active Fe decreased, aconitase activity decreased linearly, whereas the activity of glucose-6-phosphate dehydrogenase, NAD(P)-isocitrate dehydrogenase, NAD(P)-malic enzyme, malate dehydrogenase, phosphoenolpyruvate (PEP) carboxylase, PEP phosphatase, and pyruvate kinase increased curvilinearly. Glucose-6-phosphate, fructose-6-phosphate, and 3-phosphoglycerate content decreased curvilinearly as active Fe decreased. Malate content increased as active Fe increased to $1.0 \mathrm{mg} \cdot \mathrm{m}^{-2}$ and then decreased above this level. Citrate increased linearly as active Fe decreased and was an order of magnitude lower than malate content. Our results suggest that leaf FCR activity may limit Fe assimilation to a greater extent than root FCR activity. The decreased leaf aconitase activity under Fe deficiency is the most likely cause of the increase in citrate levels. Greater activity of the other glycolytic and TCA enzymes under Fe deficiency may help to funnel carbon into the mitochondria and enhance NAD(P) reduction. Citrate levels (and the citrate:malate ratios) in the xylem exudate and leaf were much lower when compared with other species and may be linked to $\mathrm{Fe}$ inefficiency of 'Concord'.
\end{abstract}

Chlorosis from lime-induced Fe deficiency limits grapevine (Vitis L.) growth and productivity (Bavaresco et al., 2003; Gruber and Kosegarten, 2002; Mengel et al., 1984a). As soil pH increases, Fe solubility decreases, and an increase in soil $\mathrm{pH}$ by one unit decreases $\mathrm{Fe}^{3+}$ activity 1000 -fold (Lindsay and Schwab, 1982). 'Concord' grapevines (V. labruscana) are particularly susceptible to lime-induced chlorosis, and this situation can be made worse under conditions of high soil moisture and low soil temperature (Davenport and Stevens, 2006).

When Fe is limiting, dicotyledons can facilitate Fe uptake by acidifying the rhizosphere to increase Fe solubility and exuding organic acids and phenolics to chelate Fe (de Vos et al., 1986; Marschner et al., 1986; Römheld and Marschner, 1983). In addition, roots can increase the activity of plasma membranebound ferric chelate reductase (FCR), which uses cytosolic

Received for publication 5 Aug. 2006. Accepted for publication 27 Mar. 2007. This work was supported in part by the USDA-ARS Northwest Center for Small Fruits Research and the NY Wine/Grape Foundation. The nutrients, lime, and medium used in this study were provided by GreenCare Fertilizers, MS Lime, and Conrad Fafard, respectively.

We gratefully acknowledge the technical assistance of Scott G. V. Henning, Richard Raba and Dr. Rui Zhou.

${ }^{1}$ Former graduate student, currently Assistant Professor in The Department of Plant Sciences, University of Tennessee, Knoxville, TN 37996.

${ }^{2}$ Corresponding author. E-mail: LC89@Cornell.edu.
$\mathrm{NAD}(\mathrm{P}) \mathrm{H}$ to cleave $\mathrm{Fe}(\mathrm{III})$-chelates and reduce $\mathrm{Fe}^{3+}$ to $\mathrm{Fe}^{2+}$ before transport across the membrane by inducible $\mathrm{Fe}^{2+}$ transporters (Chaney et al., 1972; Vert et al., 2002). Reduction of $\mathrm{Fe}$ (III)-chelates is proposed to be the rate-limiting step for $\mathrm{Fe}$ assimilation in dicotyledons (Grotz and Guerinot, 2002), and root FCR activity is often higher in Fe-efficient vs. Feinefficient species (Brancadoro et al., 1995; Römheld and Marschner, 1981).

Iron is transported to the leaves primarily as $\mathrm{Fe}(\mathrm{III})$-citrate, although there is some evidence that nicotianamine and carboxylic acids such as malate may play a role in $\mathrm{Fe}$ transport (Rombolà et al., 2000; Tiffin, 1970; von Wiren et al., 1999). Foliar Fe assimilation is dependent on FCR activity to reduce $\mathrm{Fe}(\mathrm{III})$-chelates and provide $\mathrm{Fe}^{2+}$ for transport across the mesophyll plasma membrane (Brüggemann et al., 1993). Unlike root FCR, foliar FCR does not appear to be induced by Fe deficiency; however, foliar FCR activity is regulated by light (Brüggemann et al., 1993; de la Guardia and Alcantara, 1996; Gonzalez-Vallejo et al., 2000; Larbi et al., 2001).

It has been proposed that bicarbonate uptake increases the $\mathrm{pH}$ of xylem sap and leaf apoplast and interferes with foliar Fe utilization (Mengel et al., 1984a, 1984b), but this is not wellagreed on. For instance, the xylem sap $\mathrm{pH}$ of corn (Zea mays L.) seedlings increased 0.6 and 1.1 units when supplied with 5 to $20 \mathrm{mM} \mathrm{HCO}_{3}{ }^{-}$in the nutrient solution (Wegner and Zimmermann, 2004), and López-Millàn et al. (2001b) found that the pH of the 
apoplast in Fe-deficient pear (Pyrus communis L.) leaves was 6.5 to 6.6 , whereas the apoplast $\mathrm{pH}$ of green leaves was lower, from 5.5 to 5.9. Yet on the other hand, Nikolic and Römheld (2002) found that the addition of $10 \mathrm{mM} \mathrm{HCO}_{3}{ }^{-}$to the nutrient solution did not change the $\mathrm{pH}$ of the leaf apoplastic fluid in sunflower and that there was no difference in the leaf apoplast $\mathrm{pH}$ between chlorotic and field-grown Vitis vinifera L. In addition to bicarbonate, nitrate may also influence the $\mathrm{pH}$ of the xylem sap and leaf apoplast and impact Fe assimilation, but this is not fully supported either (Kosegarten et al., 2001; Lucena, 2000; Nikolic and Römheld, 2003).

The accumulation of organic acids, primarily malate and citrate, commonly occurs in iron-deficient roots and leaves (Abadía et al., 2002). For example, citrate and malate increased in the root tips of four different grapevine genotypes in response to $\mathrm{Fe}$ limitation, and chlorosis-resistant genotypes contained higher levels of organic acids (Ollat et al., 2003). An increase in malate and citrate in response to Fe deficiency has a number of potential benefits. Increased root exudation of citric and malic acid will improve soil $\mathrm{Fe}$ availability both through chelation and rhizosphere acidification (Jones, 1998; Landsberg, 1981). In addition, greater concentrations of citrate could also aid in transport of Fe in the xylem (Tiffin, 1970).

It is not clear, however, why organic acids accumulate in $\mathrm{Fe}$-deficient tissues. Citrate accumulation in Fe-deficient plants was originally thought to result from a decreased conversion of citrate to isocitrate by aconitase, which requires $\mathrm{Fe}$ as a cofactor (Bacon et al., 1961). However, aconitase activity is not consistently decreased under Fe deficiency (de Vos et al., 1986; López-Millàn et al., 2001a). Alternatively, organic acid accumulation could result from increased carbon fixation by phosphoenolpyruvate (PEP) carboxylase when soil $\mathrm{HCO}_{3}{ }^{-}$is high or Fe is limiting. According to this theory, high rates of $\mathrm{H}^{+}$efflux under $\mathrm{Fe}$ deficiency would increase the $\mathrm{pH}$ of the cytoplasm and activate PEP carboxylase (Felle, 1988; Rabotti et al., 1995). Carboxylation of PEP through PEP carboxylase would result in oxaloacetate (OAA) and malate synthesis and a lowering of cytosolic pH (Davies, 1986).

Considering the importance of FCR and organic acids in Fe assimilation, there were two main objectives for our work with low pH-tolerant (Fe-inefficient) 'Concord' grapevines. The first objective was to characterize root and leaf ferric chelate reductase activity in response to lime-induced Fe limitation. The second objective was to quantify how lime-induced Fe limitation affects key enzymes and metabolites involved with glycolysis and the tricarboxylic acid cycle in leaves. We hypothesized that Fedeficient leaves would have lower aconitase activity and that this would result in an accumulation of citrate. We also hypothesized that an increase in $\mathrm{CaCO}_{3}$ in the rooting medium would raise the xylem sap $\mathrm{pH}$ and negatively impact Fe utilization.

\section{Materials and Methods}

Two separate experiments were conducted using a peat/ perlite medium (starting $\mathrm{pH} 4.5$ ) that was adjusted to different pHs using $\mathrm{CaCO}_{3}$. We provided the vines with all essential nutrients except $\mathrm{Fe}$ as a way of ensuring that the lime-induced chlorosis was primarily the result of Fe limitation. By omitting $\mathrm{Fe}$ from the nutrient solution, and providing other micronutrients as sulfate salts, we could avoid any complications from the use of synthetic chelates and allow the vines to mine for Fe from the peat and perlite.
Expt. 1: Root and leaf ferric chelate reductase activity in 'Concord' grapevines grown at three different root-medium pHs

Plant Culture and treatments. Own-rooted 1-year-old 'Concord' grapevines were transplanted into 19.8-L plastic pots containing $80 \%$ peat: $20 \%$ perlite (v:v) (Conrad Fafard, Agawam, MA) and grown for 9 weeks in a greenhouse. Substrate $\mathrm{pH}$ was adjusted with $2.1,2.8$, or $16.3 \mathrm{~kg} \cdot \mathrm{m}^{-3} \mathrm{CaCO}_{3}($ Grade R2; Mississippi Lime, St. Genevieve, MO), and the $\mathrm{pH}$ of a 1:2 (v/v) substrate:deionized $\mathrm{H}_{2} \mathrm{O}$ mixture after 4 weeks was $5.8 \pm$ $0.1,6.8 \pm 0.3$, or $7.5 \pm 0.1$, respectively. There were five threeplant replicates per $\mathrm{pH}$ treatment in a randomized complete block design.

Once a week, each plant received $1 \mathrm{~L}$ of a water-soluble fertilizer with all essential nutrients except Fe. Nutrients were blended based on Hoagland's No. 2 solution by GreenCare Fertilizers (Chicago) and applied at a rate of (in $\left.\mathrm{mg} \cdot \mathrm{L}^{-1}\right) 210 \mathrm{~N}$, $31 \mathrm{P}, 235 \mathrm{~K}, 160 \mathrm{Ca}, 49 \mathrm{Mg}, 0.50 \mathrm{Mn}, 0.05 \mathrm{Zn}, 0.02 \mathrm{Cu}, 0.01$ $\mathrm{Mo}$, and $0.49 \mathrm{~B}$. Micronutrient cations were applied as sulfate salts, and solution was supplemented with $80 \mathrm{mg} \cdot \mathrm{L}^{-1} \mathrm{~K}$ from $\mathrm{KCl}$.

At budbreak, extra shoots were removed and two shoots were allowed to grow on each plant. Nine weeks after transplanting, the youngest fully expanded leaf from one shoot per replication was selected for foliar FCR, chlorophyll, and total and active $\mathrm{Fe}$ analysis. After collecting leaves, root tips from one plant per replication were collected for root FCR measurements.

LEAF AND ROOT FERRIC CHELATE REDUCTASE ASSAY AND FE ANALYSIS. Foliar FCR was assayed according to Rombolà et al. (2000) and de la Guardia and Alcantara (1996) with some modifications. During midday, 12 leaf discs $\left(0.5 \mathrm{~cm}^{2}\right.$ each) were punched from each leaf and immediately placed in $5 \mathrm{~mL}$ of ice-cold $50 \mathrm{~mm}$ MES [2-(N-Morpholino)ethanesulfonic acid]- $\mathrm{KOH}$ pH 5.5, $500 \mathrm{~mm}$ sorbitol, $1 \mathrm{mM} \mathrm{CaCl}_{2}$, and $1 \%$ bovine serum albumin (BSA) and kept on ice until all discs were punched. Discs were rinsed twice with $5 \mathrm{~mL}$ of ice-cold rinse buffer (50 mM MES-KOH pH 6.5, $500 \mathrm{~mm}$ sorbitol, $1 \mathrm{~mm}$ $\left.\mathrm{CaCl}_{2}\right)$ and then were vacuum-infiltrated $(5 \mathrm{kPa})$ for $20 \mathrm{~min}$ in $5 \mathrm{~mL}$ of rinse buffer. FCR activity was determined in $3 \mathrm{~mL}$ of $50 \mathrm{~mm}$ MES-KOH pH 6.5. $0.5 \mathrm{~mm} \mathrm{CaSO}_{4}, 500 \mathrm{~mm}$ sorbitol, $1 \mathrm{~mm}$ $\mathrm{KCl}$, and $750 \mu \mathrm{M}$ BPDS. The reaction was initiated with $250 \mu \mathrm{M}$ $\mathrm{Fe}(\mathrm{III})$-ethylenediaminetetraacetic acid (EDTA), and the discs were shaken under $5 \mathrm{kPa}$ vacuum and $\approx 200 \mu \mathrm{mol} \cdot \mathrm{m}^{-2} \cdot \mathrm{s}^{-1}$ light at sample level $(\lambda>600 \mathrm{~nm}$ filtered with red plastic) for $30 \mathrm{~min}$ at $25{ }^{\circ} \mathrm{C}$. The absorbance of Fe(II)-BPDS was determined at $535 \mathrm{~nm}$ against a no-sample blank, and $\mathrm{Fe}^{2+}$ concentration was calculated using a molar extinction coefficient of 22.14 $\mathrm{mm}^{-1} \cdot \mathrm{cm}^{-1}$ (Chaney et al., 1972). To correct for nonenzymatic reduction, samples were also shaken in assay buffer without $\mathrm{Fe}(\mathrm{III})$-EDTA. After $30 \mathrm{~min}$, an aliquot was removed, mixed with $250 \mu \mathrm{M}$ Fe(III)-EDTA, and placed in darkness for $30 \mathrm{~min}$.

After leaf FCR measurements, chlorophyll was extracted from two leaf discs (1.2 $\mathrm{cm}^{2}$ each) according to Arnon (1949). Leaves were then rinsed in deionized $\mathrm{H}_{2} \mathrm{O}$ and dried at $70{ }^{\circ} \mathrm{C}$ for $7 \mathrm{~d}$. Total and active $\mathrm{Fe}$ was determined according to Smith and Cheng (2006).

Root FCR was determined as described by Poonnachit and Darnell (2004). Root tips ( $\approx 1 \mathrm{~cm}$ long) were cut and placed in $20 \mathrm{~mL}$ of ice-cold $0.5 \mathrm{~mm} \mathrm{CaCl}_{2}$ and $1 \% \mathrm{BSA}$ and kept on ice until all roots were harvested. Root tips were rinsed in $10 \mathrm{~mL}$ of ice-cold $0.5 \mathrm{mM} \mathrm{CaCl}_{2}$, and then $\approx 100 \mathrm{mg}$ were transferred to $5 \mathrm{~mL}$ of $10 \mathrm{~mm}$ MES-KOH pH 5.5, $0.2 \mathrm{~mm} \mathrm{CaSO}_{4}$, and $750 \mu \mathrm{M}$ 
BPDS. The reaction was initiated with $250 \mu \mathrm{M}$ Fe(III)-EDTA, and samples were shaken in the dark for $60 \mathrm{~min}$ at $25^{\circ} \mathrm{C} . \mathrm{Fe}^{2+}$ concentration was determined as described for foliar FCR and corrected for nonenzymatic reduction by shaking root tips in assay buffer without Fe(III)-EDTA for $60 \mathrm{~min}$ in the dark and then mixing an aliquot with $250 \mu \mathrm{M} \mathrm{Fe}(\mathrm{III})$-EDTA and shaking for an additional $60 \mathrm{~min}$ in the dark.

\section{Expt. 2: Effect of root-medium pH on carbon metabolism in 'Concord' grapevines}

Plant Culture and treatments. Own-rooted 1-year-old 'Concord' grapevines were transplanted on 5 May 2005 into 19.8-L plastic pots containing $80 \%$ peat: $20 \%$ perlite (v:v) and grown outdoors from 17 May 2005 to 29 Sept. 2005. Substrate $\mathrm{pH}$ was adjusted with $1.4,2.1,2.8,4.1$, or $16.3 \mathrm{~kg} \cdot \mathrm{m}^{-3} \mathrm{CaCO}_{3}$, and the mean pH over 9 weeks (measured on weeks 1, 5, and 9) was $5.1 \pm 0.1,5.7 \pm 0.1,6.6 \pm 0.0,7.1 \pm 0.0$, or $7.5 \pm 0.1$, respectively. There were five three-plant replicates per $\mathrm{pH}$ treatment in a completely randomized design.

At budbreak, extra shoots were removed and two shoots were allowed to grow on each plant. Twice per week, each plant received $1 \mathrm{~L}$ of the same nutrient solution used in Expt. 1 with no applied Fe. Nine weeks after transplanting, the youngest fully expanded leaf from one shoot per replicate was chosen for analysis during midday, and the corresponding leaf on the second shoot was selected for analysis during the night. In addition, 30-cm shoot tips were harvested from another shoot per replicate, and xylem sap was expressed using a Scholander pressure bomb.

XYlem SAP COLlection AND ANALYSIS. Approximately $500 \mu \mathrm{L}$ of xylem sap was expressed at $2 \mathrm{MPa}$ and collected in a 1.5-mL microcentrifuge tube by resting the pressure bomb on its side and allowing the sap to drip into the tube. The phloem was stripped from $1.5 \mathrm{~cm}$ of the shoot tip, and the tip was blotted several times with a paper towel before collection. The $\mathrm{pH}$ of the sap was measured immediately with a micro $\mathrm{pH}$ electrode (9802BN; Thermo Orion, Waltham, MA). Sap was stored at $-80{ }^{\circ} \mathrm{C}$ until it was analyzed for total $\mathrm{Fe}$, citrate, and malate.

Total $\mathrm{Fe}$ in the xylem sap was determined essentially as described for the analysis of active Fe in leaves (Smith and Cheng, 2006) with the exception that $50 \mu \mathrm{L}$ of sap was mixed with $50 \mu \mathrm{L}$ of $4 \%(\mathrm{v} / \mathrm{v}) \mathrm{HClO}_{4}$ and allowed to sit for $1 \mathrm{~h}$ before analysis. Citrate and malate in the xylem sap were assayed according to Passonneau and Lowry (1993) with some modifications. Citrate was quantified in a $1-\mathrm{mL}$ mixture containing $200 \mathrm{~mm}$ HEPES [4-(2-Hydroxyethyl)piperazine1-ethanesulfonic acid]-KOH pH 7.5, $200 \mu \mathrm{M} \mathrm{ZnSO}_{4}, 200 \mu \mathrm{M}$ $\mathrm{NADH}, 5$ units of malate dehydrogenase, 4 units of lactate dehydrogenase, $20 \mu \mathrm{L}$ xylem sap, and 0.2 units of citrate lyase. Malate concentration was determined in a $1-\mathrm{mL}$ mixture containing $250 \mathrm{~mm}$ glycine-glycine-KOH pH 10.0, $40 \mathrm{~mm}$ glutamate-KOH pH 10.0, $2.7 \mathrm{~mm}$ NAD, 1 unit of glutamateoxaloacetate transaminase, 5 units of malate dehydrogenase, and $10 \mu \mathrm{L}$ of xylem sap. For all NAD(P)-linked assays used in these experiments, absorbance was determined at $340 \mathrm{~nm}$ and enzyme activity or metabolite concentration calculated using a molar extinction coefficient of $6.22 \mathrm{~mm} \mathrm{~m}^{-1} \cdot \mathrm{cm}^{-1}$.

GAS EXCHANGE AND CHLOROPHYLL FLUORESCENCE MEASUREMENTS. Gas exchange was measured with a CIRAS-1 system (PP Systems, Herts, UK) at ambient $\mathrm{CO}_{2}$ (360 $\mu \mathrm{mol} \cdot \mathrm{mol}^{-1}$ ) either at noon under a photon flux density of
$1606 \pm 57 \mu \mathrm{mol} \cdot \mathrm{m}^{-2} \cdot \mathrm{s}^{-1}$ and a leaf temperature of $27.4 \pm 0.8^{\circ} \mathrm{C}$ or at midnight with a leaf temperature of $17.2 \pm 0.6^{\circ} \mathrm{C}$. Chlorophyll fluorescence was measured with a pulse-modulated fluorometer (FMS2; Hansatech Instruments, Norfolk, UK) as described by Chen and Cheng (2003). Photosystem II quantum efficiency (proportion of light absorbed by PSII used in photochemistry) was measured at noon directly after gas exchange measurements and calculated as $\left(\mathrm{F}_{\mathrm{m}}{ }^{\prime}-\mathrm{F}^{\prime}\right) / \mathrm{F}_{\mathrm{m}}{ }^{\prime}$ (Genty et al., 1989). Maximum photochemical efficiency of dark-adapted leaves was determined at midnight after gas exchange measurements and was calculated as $F_{\mathrm{v}} / F_{\mathrm{m}}=$ $\left(F_{\mathrm{m}}-F_{\mathrm{o}}\right) / \mathrm{F}_{\mathrm{m}}$ (van Kooten and Snel, 1990).

Sample collection, Chlorophyll and Fe analysis. After gas exchange and fluorescence measurements, leaf discs (1.2 $\mathrm{cm}^{2}$ ) were punched from each leaf and frozen in liquid $\mathrm{N}_{2}$. Frozen leaf discs were stored at $-80{ }^{\circ} \mathrm{C}$ until analysis. Chlorophyll was extracted from two leaf discs according to Arnon (1949), and protein was quantified from two discs according to Bradford (1976). The area of the remaining leaf was measured (corrected for leaf discs removed), and then leaves were rinsed in deionized $\mathrm{H}_{2} \mathrm{O}$ and dried at $70{ }^{\circ} \mathrm{C}$ for $7 \mathrm{~d}$. Total and active Fe was determined according to Smith and Cheng (2006). At the end of the season, all leaves were harvested from one plant per replication. The total leaf area per vine was measured, leaves were dried at $70{ }^{\circ} \mathrm{C}$ for $7 \mathrm{~d}$, and then the total foliar dry weight was recorded.

Assay of ENZYMes in CARbon Metabolism. For foliar enzyme assays, two discs were ground with a precooled mortar and pestle in $2.0 \mathrm{~mL}$ of $200 \mathrm{~mm}$ HEPES [adjusted to $\mathrm{pH} 7.5$ with dry TRIS (tris (hydroxymethyl) aminomethane)], 1 mM EDTA, $5 \mathrm{~mm} \mathrm{MgSO}_{4}, 5 \mathrm{~mm}$ dithiothreitol (DTT), 1\% (w/v) Triton X-100 (Hach Co., Ames, IA), 30\% (w/v) glycerol, 8\% (w/v) polyvinylpolypyrrolidine (PVPP), and $1 \mathrm{~mm}$ phenylmethylsulfonyl fluoride (PMSF). Extract was centrifuged at $15,000 g_{n}$ for 2 min to remove PVPP, the supernatant was centrifuged again at $15,000 g_{\mathrm{n}}$ for $10 \mathrm{~min}$, and the supernatant was used immediately for the measurement of enzyme activity. Aconitase, NAD-malate dehydrogenase (MDH), and NAD-malic enzyme were measured as described by Jenner et al. (2001) with some modifications. Aconitase was assayed in a $1-\mathrm{mL}$ mixture containing $85 \mathrm{~mm}$ HEPES-KOH pH 7.5, $10 \mathrm{~mm}$ $\mathrm{MgSO}_{4}, 5 \mathrm{~mm} \mathrm{MnCl}$, $1 \mathrm{~mm}$ DTT, $0.5 \mathrm{~mm}$ NADP, 2 units of NADP-isocitrate dehydrogenase (IDH), and $75 \mu \mathrm{L}$ of enzyme extract. The reaction was initiated by adding $10 \mathrm{~mm}$ cisaconitate. NAD-malic enzyme was assayed by measuring the amount of pyruvate produced from malate in a $250-\mu \mathrm{L}$ mixture containing $100 \mathrm{~mm}$ imidazole- $\mathrm{HCl} \mathrm{pH} 7.0,10 \mathrm{~mm} \mathrm{MgSO}_{4}$, $50 \mu \mathrm{M}$ coenzyme A, $4 \mathrm{~mm}$ NAD, and $50 \mu \mathrm{L}$ enzyme extract. The reaction was initiated with $20 \mathrm{~mm}$ malate and allowed to run for $15 \mathrm{~min}$ at $25^{\circ} \mathrm{C}$ and then stopped by boiling for $2 \mathrm{~min}$. Pyruvate was determined in a $1-\mathrm{mL}$ mixture containing $100 \mathrm{~mm}$ imidazole- $\mathrm{HCl} \mathrm{pH} 7.0,250 \mu \mathrm{M} \mathrm{NADH}, 20 \mathrm{~mm} \mathrm{KCl}, 1 \mathrm{~mm}$ ADP, and a $100-\mu \mathrm{L}$ aliquot of the sample. The reaction was initiated with 5 units of lactate dehydrogenase. NAD-MDH was assayed in a 1-mL mixture containing $100 \mathrm{~mm}$ MOPS [3-(NMorpholino)propanesulfonic acid]-KOH pH 7.0, $5 \mathrm{~mm} \mathrm{MgSO}_{4}$, $1 \mathrm{~mm}$ DTT, $1 \mathrm{~mm}$ EDTA, $250 \mu \mathrm{M}$ NADH, and $5.0 \mu \mathrm{L}$ sample. The reaction was initiated with $1 \mathrm{~mm}$ oxaloacetate.

NADP-malic enzyme, glucose-6-phosphate dehydrogenase (G6PDH), and NAD(P)-IDH were assayed according to Passonneau and Lowry (1993) with some modifications. NADPmalic enzyme activity was measured in a $1-\mathrm{mL}$ mixture 
containing $100 \mathrm{~mm}$ Bicine- $\mathrm{KOH}$ pH 8.0, $5 \mathrm{~mm} \mathrm{MgSO}_{4}, 5 \mathrm{~mm}$ $\mathrm{MnCl}_{2}, 0.5 \mathrm{~mm} \mathrm{NADP}$, and $75 \mu \mathrm{L}$ of enzyme extract. The reaction was initiated with $5 \mathrm{~mm}$ malate. G6PDH was assayed in a 1-mL mixture containing $100 \mathrm{~mm}$ TRIS-HCl pH 8.0, $1 \mathrm{~mm}$ EDTA, $5 \mathrm{~mm} \mathrm{MgSO}_{4}, 5 \mathrm{~mm} \mathrm{KCl}, 0.5 \mathrm{~mm}$ NADP, and $40 \mu \mathrm{L}$ enzyme extract and the reaction was initiated with $3 \mathrm{~mm}$ glucose-6-phosphate (G6P). NAD-IDH activity was measured in a 1-mL mixture containing $100 \mathrm{~mm}$ HEPES-KOH pH 7.5, $5 \mathrm{~mm} \mathrm{MnCl}_{2}, 2 \mathrm{~mm} \mathrm{NAD}$, and $150 \mu \mathrm{L}$ of sample. The reaction was initiated with $5 \mathrm{~mm}$ isocitrate. NADP-IDH was assayed in a $1-\mathrm{mL}$ mixture containing $100 \mathrm{~mm}$ Bicine-KOH pH 8.0, $5 \mathrm{~mm}$ $\mathrm{MgSO}_{4}, 5 \mathrm{~mm} \mathrm{KCl}, 0.5 \mathrm{~mm} \mathrm{NADP}$, and $50 \mu \mathrm{L}$ of enzyme extract. The reaction was initiated with $5 \mathrm{~mm}$ isocitrate.

Pyruvate kinase (PK) and PEP phosphatase were assayed according to Plaxton (1990) with some modifications. Pyruvate kinase was determined in a $1-\mathrm{mL}$ reaction containing $100 \mathrm{~mm}$ imidazole- $\mathrm{HCl} \mathrm{pH} 7.0,50 \mathrm{~mm} \mathrm{KCl}, 10 \mathrm{~mm} \mathrm{MgCl}_{2}, 0.05 \% \mathrm{BSA}$, 2 mм DTT, $150 \mu \mathrm{M}$ NADH, 1 unit lactate dehydrogenase, $2 \mathrm{~mm}$ ADP, and $100 \mu \mathrm{L}$ enzyme extract. The reaction was initiated with $2 \mathrm{~mm}$ PEP. PEP phosphatase was determined under the same conditions with the omission of ADP, and PK activity was corrected for PEP phosphatase activity. PEP carboxylase was determined according to Stitt et al. (1989) in a $250 \mu \mathrm{L}$ mixture containing $100 \mathrm{~mm}$ Bicine-KOH pH 8.0, $2 \mathrm{~mm}\left[{ }^{14} \mathrm{C}\right] \mathrm{K}_{2} \mathrm{CO}_{3}, 10 \mathrm{~mm}$ $\mathrm{MgSO}_{4}, 350 \mu \mathrm{M} \mathrm{NADH}, 10$ units of malate dehydrogenase, and $2 \mathrm{~mm}$ PEP. The reaction was initiated with $25 \mu \mathrm{L}$ enzyme extract and stopped after $15 \mathrm{~min}$ with the addition of $500 \mu \mathrm{L}$ of $0.5 \mathrm{~N} \mathrm{HCl}$. The solution was dried overnight at 50 to $70{ }^{\circ} \mathrm{C}$ and redissolved in $200 \mu \mathrm{L} \mathrm{H}_{2} \mathrm{O}$ and $3 \mathrm{~mL}$ of scintillation fluid.

EXTRACTION AND ASSAY OF METABOLITES. Metabolites were extracted from the leaves according to Leegood (1993). Eight discs were ground with a precooled mortar and pestle in $1.5 \mathrm{~mL}$ of ice-cold 4\% (v/v) $\mathrm{HClO}_{4}$. Extract was added to a microcentrifuge tube containing $50 \mathrm{mg} \mathrm{HCl}$-washed activated charcoal. The mortar and pestle was rinsed with $0.5 \mathrm{~mL}$ of $4 \%(\mathrm{v} / \mathrm{v})$ $\mathrm{HClO}_{4}$ and added to the same tube. The extract sat on ice for 30 min and then was centrifuged at $15,000 g_{n}$ for $10 \mathrm{~min}$. A $1.5-\mathrm{mL}$ aliquot of the supernatant was removed and neutralized to $\mathrm{pH} 6$ with $200 \mu \mathrm{L}$ of $5 \mathrm{M} \mathrm{KOH}$ in $1 \mathrm{M}$ triethanolamine. Sample was mixed with $50 \mathrm{mg}$ PVPP and then allowed to sit on ice for 15 min to precipitate $\mathrm{KClO}_{4}$ and remove any remaining phenolics. Extract was centrifuged at $15,000 g_{\mathrm{n}}$ for $10 \mathrm{~min}$, and the supernatant was stored at $-80{ }^{\circ} \mathrm{C}$ until analysis.

Before metabolite analysis, samples were thawed and centrifuged at $15,000 \mathrm{~g}_{\mathrm{n}}$ for $10 \mathrm{~min}$ to remove any remaining $\mathrm{KClO}_{4}$. Fructose-6-phosphate (F6P), G6P, and 3-phosphoglyerate (PGA) concentration was determined according to Leegood (1993). G6P was measured in a 1-mL mixture containing 100 mm TRIS-HCl pH 8.0, 1 mм EDTA, 5 mm $\mathrm{MgSO}_{4}, 5 \mathrm{~mm} \mathrm{KCl}$, $500 \mu \mathrm{M}$ NAD, 1 unit G6PDH, and $200 \mu \mathrm{L}$ of sample. F6P was determined in the same cuvette with the addition of 1 unit of phosphoglucose isomerase. PGA was quantified in a 1-mL mixture containing $50 \mathrm{~mm}$ imidazole- $\mathrm{HCl} \mathrm{pH} 7.0,2 \mathrm{mM} \mathrm{MgCl}_{2}$, $5 \mathrm{~mm}$ ATP, $20 \mathrm{~mm} \mathrm{NaCl}, 2 \mathrm{~mm} \beta$-mercaptoethanol, $200 \mu \mathrm{M}$ NADH, 5 units glyceraldehyde-3-phosphate dehydrogenase, 5 units of PGA kinase, and $100 \mu \mathrm{L}$ of extract. Citrate and malate were assayed as previously described. Unless otherwise indicated, all enzyme and metabolites were measured against a nosample blank, and reactions containing sample were also run without substrate when necessary.

Statistical analysis. Analysis of variance was performed using JMP (version 5.1; SAS Institute, Cary, NC), and regressions were performed using SigmaPlot (version 9.0; Systat Software, Point Richmond, CA). Open circles in the figures reflect data collected at noon, and black circles represent data collected at midnight. In situations in which data collection time was not significant $(P>0.05)$, treatments were grouped together and are indicated by gray circles. Error bars represent the standard error of the mean.

\section{Results}

For the greenhouse experiment, vines grown at the lowest $\mathrm{pH}$ treatment were healthy and green, and an increase in root-medium $\mathrm{pH}$ decreased the concentration of $\mathrm{Chl}$, total $\mathrm{Fe}$, and active $\mathrm{Fe}$ in the leaves (Table 1). Leaf total $\mathrm{Fe}$ at the highest $\mathrm{pH}$ was $\approx 50 \%$ lower than the amount found in vines grown at the lowest $\mathrm{pH}$, whereas $\mathrm{Chl}$ and active Fe concentrations were $84 \%$ lower. As $\mathrm{pH}$ increased from 5.8 to 7.5, root FCR activity increased 10-fold, whereas leaf FCR activity decreased 10-fold (Table 1).

In the second experiment, as root-medium $\mathrm{pH}$ increased from 5.1 to 7.5 , both the total leaf area and the total foliar dry weight per vine decreased curvilinearly (Fig. 1A). The total and active Fe content of recently matured leaves also decreased curvilinearly as $\mathrm{pH}$ rose with a greater decrease in active $\mathrm{Fe}$ compared with total Fe (Fig. 2A-B). Active Fe content is often a better indicator of foliar Fe nutritional status (Gezgin and Er, 2001; Oserkowsky, 1933; Smith and Cheng, 2005), and the remaining foliar data are presented in relation to leaf active Fe content.

As leaf active Fe content decreased, the area of the recently matured leaf selected for biochemical analysis also decreased (Fig. 3A). The Chl content of fresh leaves was highly correlated to active Fe content $\left(\mathrm{R}^{2}=0.88\right.$; Fig. $\left.3 \mathrm{~B}\right)$ and decreased as active $\mathrm{Fe}$ decreased. Protein decreased linearly as active Fe decreased (Fig. 3C).

At midday, $\mathrm{CO}_{2}$ assimilation, $g_{\mathrm{S}}$, and PSII quantum efficiency decreased from maximum levels in leaves with a high active Fe content to very low levels in leaves with the lowest active $\mathrm{Fe}$ content (Fig. 4A, B, and D). Internal $\mathrm{CO}_{2}$ increased curvilinearly as active Fe decreased (Fig. 4C). The maximum PSII efficiency of dark-adapted leaves was decreased only at

Table 1. Chlorophyll concentration (Chl), leaf total and active Fe concentration, and root and leaf ferric chelate reductase (FCR) activity in 'Concord' grapevine in response to $\mathrm{pH}$ treatment. ${ }^{\mathrm{z}}$

\begin{tabular}{lccccc}
\hline $\mathrm{pH}$ & $\mathrm{Chl}\left(\mathrm{mg} \cdot \mathrm{g}^{-1}\right)$ & Total Fe $\left(\mu \mathrm{g} \cdot \mathrm{g}^{-1}\right)$ & Active Fe $\left(\mu \mathrm{g} \cdot \mathrm{g}^{-1}\right)$ & Root FCR $\left(\mathrm{nmol} \cdot \mathrm{g}^{-1} \cdot \mathrm{min}^{-1}\right)$ & ${\mathrm{Leaf} \mathrm{FCR}\left(\mathrm{nmol} \cdot \mathrm{g}^{-1} \cdot \mathrm{min}^{-1}\right)}$ \\
\hline 5.8 & $1.9 \pm 0.1$ & $93.7 \pm 7.3$ & $22.5 \pm 1.7$ & $0.8 \pm 0.3$ & $9.0 \pm 1.9$ \\
6.8 & $1.3 \pm 0.1$ & $59.4 \pm 6.3$ & $10.5 \pm 0.6$ & $2.8 \pm 1.1$ & $2.9 \pm 0.6$ \\
7.5 & $0.3 \pm 0.1$ & $46.0 \pm 4.3$ & $3.4 \pm 0.9$ & $8.1 \pm 1.0$ & $0.9 \pm 0.5$ \\
$P$ & $* * *$ & $* * *$ & $* * *$ & $* * *$ & $* *$
\end{tabular}

${ }^{\mathrm{z} F C R}$ activity and chlorophyll are expressed on a fresh weight basis, and Fe concentration on a dry weight basis. Data are means $\pm \mathrm{SE}(\mathrm{n}=5)$.

${ }^{* * * * * *}$ Analysis of variance results: $P<0.01$ and 0.001 , respectively. 

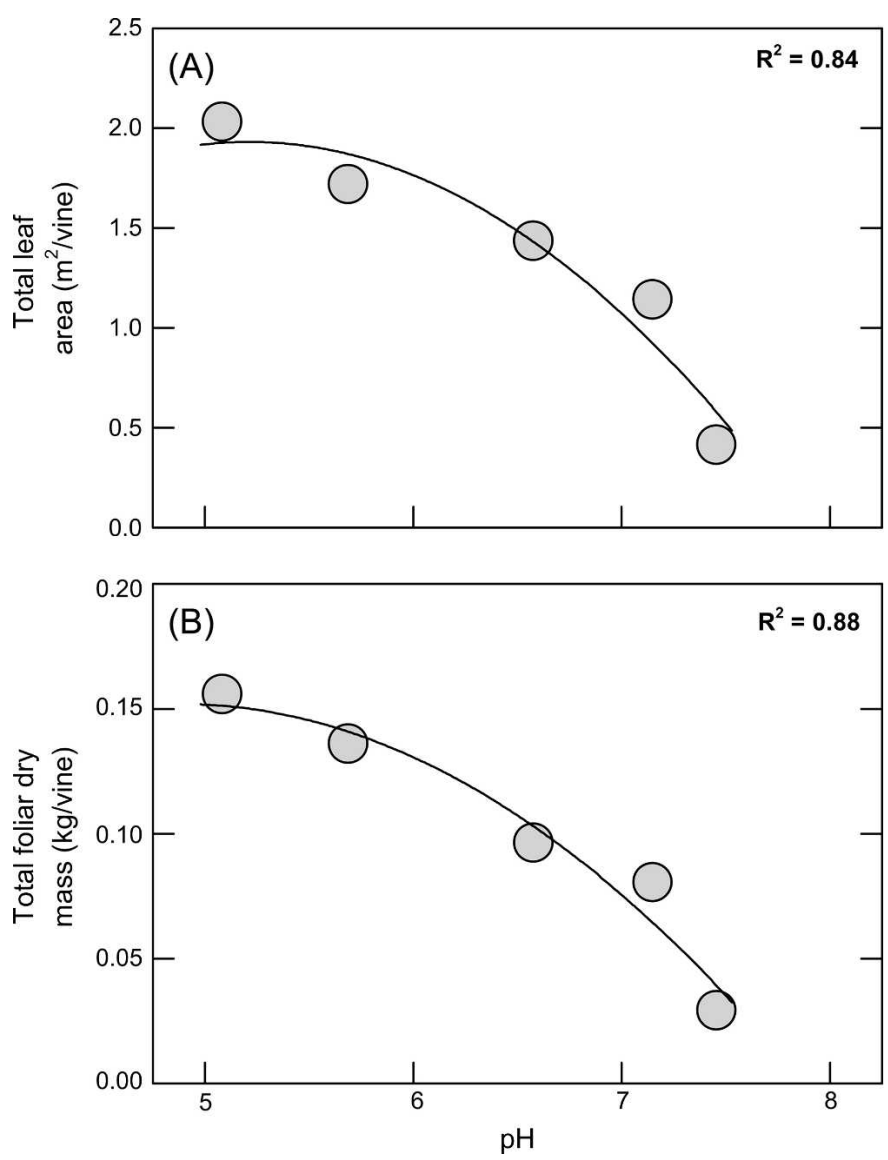

Fig. 1. (A) Total leaf area per vine and (B) total foliar dry weight at the end of the season in 'Concord' grapevines grown at five different pHs $(\mathrm{n}=5)$. Regression equations for $(\mathbf{A}) y=-5.38+2.80 x-0.27 x^{2}\left(R^{2}=0.84, P<0.001\right)$ and (B) $y=-0.25+0.17 x-0.02 x^{2}\left(R^{2}=0.88, P<0.001\right)$.

the lowest active $\mathrm{Fe}$ content, and night respiration rate decreased curvilinearly as active Fe decreased (Fig. 4E-F).

Activity of G6PDH, aconitase, and both NAD(P) isoforms of IDH and malic enzyme was greater at midnight vs. midday (Fig. 5A-D, F, and G), whereas sampling time did not affect the activity of NAD-MDH, PEP carboxylase, PEP phosphatase, or PK (Fig. 5E and H-J). With the exception of aconitase, all other enzymes responded similarly to active Fe. Enzyme activity increased as active $\mathrm{Fe}$ decreased below $1.0 \mathrm{mg} \cdot \mathrm{m}^{-2}$, whereas above $1.0 \mathrm{mg} \cdot \mathrm{m}^{-2}$, activity did not change or increased slightly (Fig. 5A and C-J). On the other hand, aconitase activity, and the difference between day and night measurements, decreased as active Fe decreased (Fig. 5B).

G6P, F6P, and PGA decreased curvilinearly as active Fe decreased; G6P content was greater at night, whereas F6P and PGA content was higher during the day (Fig. 6A-C). Malate content was the lowest in leaves with the lowest active Fe and increased as active $\mathrm{Fe}$ increased to $1.0 \mathrm{mg} \cdot \mathrm{m}^{-2}$ (Fig. 6D). Above $1.0 \mathrm{mg} \cdot \mathrm{m}^{-2}$ active $\mathrm{Fe}$, malate content decreased, and leaves sampled during the night had significantly lower malate (Fig. 6D). Citrate content increased linearly as active Fe decreased and was not influenced by the time of day (Fig. 6E). Foliar citrate levels were greater than 10 times less than malate levels.

In the xylem sap, an increase in root-medium $\mathrm{pH}$ did not correspond to an increase in xylem sap $\mathrm{pH}$, and the xylem sap $\mathrm{pH}$ was $\approx 5.5$ across all treatments (Fig. $7 \mathrm{~A} ; P=$ not significant).
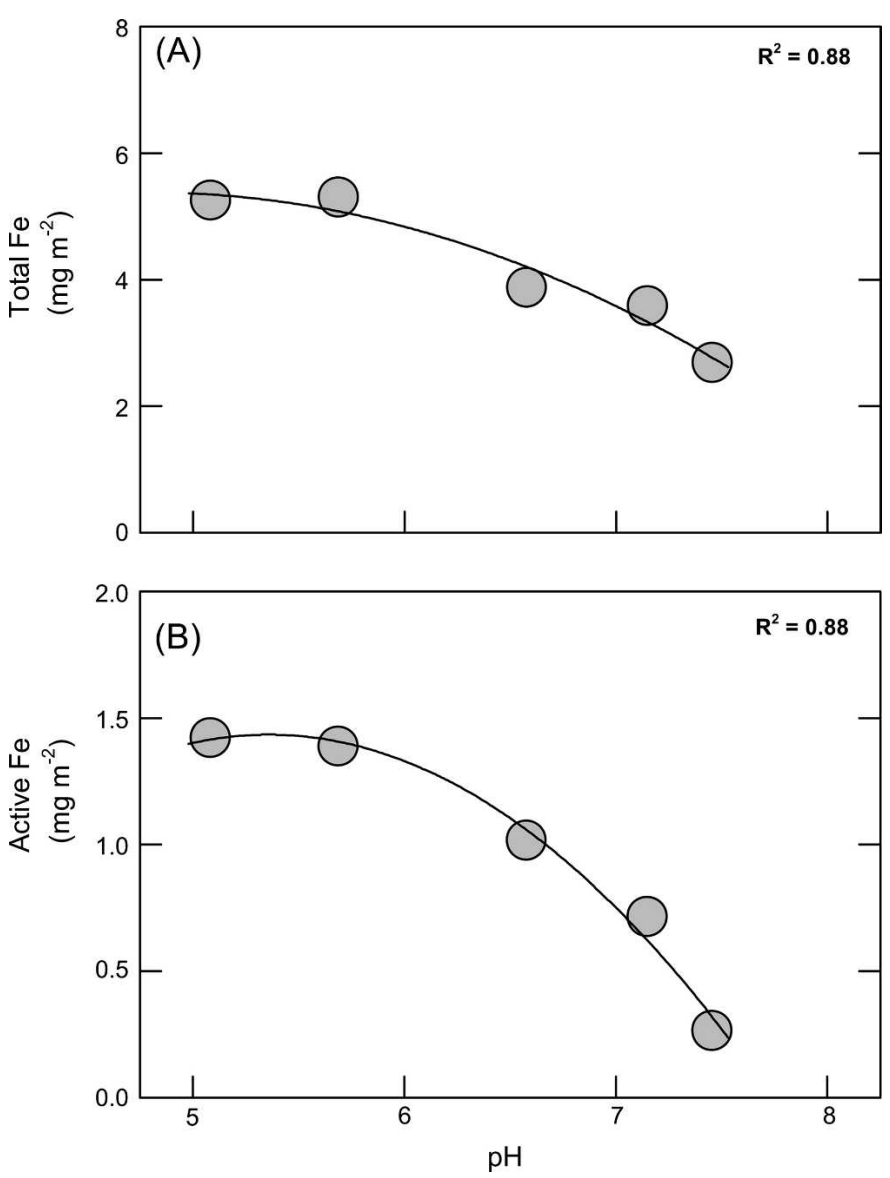

Fig. 2. (A) Total Fe and (B) active Fe in recently matured leaves of 'Concord' grapevines grown at five different $\mathrm{pHs}(\mathrm{n}=5)$. Regression equations for (A) $y=-3.00+3.50 x-0.37 x^{2}\left(R^{2}=0.88, P<0.001\right)$ and (B) $y=-5.86+$ $2.72 x-0.25 x^{2}\left(R^{2}=0.88, P<0.001\right)$. Iron content is expressed on an area basis in this experiment to relate it to other parameters measured on an area basis. For reference purposes, total Fe ranged from 40 to $75 \mu \mathrm{g} \cdot \mathrm{g}^{-1}$ and active Fe from 4 to $20 \mu \mathrm{g} \cdot \mathrm{g}^{-1}$ on a dry weight basis.

The concentration of Fe in the xylem exudate decreased as soil $\mathrm{pH}$ increased from 5.1 to 6.6 and then increased slightly as $\mathrm{pH}$ increased above 6.6 (Fig. 7B). Xylem citrate concentration decreased above pH 6.6 (Fig. 7C), whereas malate increased from $\mathrm{pH} 5.1$ to $\mathrm{pH} 6.6$ and then decreased above $\mathrm{pH} 6.6$ (Fig. 7D).

\section{Discussion}

In both experiments, total $\mathrm{Fe}$ and active $\mathrm{Fe}$ was lower in leaves with lime-induced chlorosis (Table 1; Fig. 2A-B). Previously, we reported that chlorotic leaves from 'Concord' vines can contain as much or more total $\mathrm{Fe}$ than green leaves and that active Fe provides a better relationship with $\mathrm{Chl}$ (Smith and Cheng, 2005, 2006). It is possible that the reason we observed a decrease in foliar total $\mathrm{Fe}$ in this study, but not in the other experiments, is related to a treatment effect. The treatment in this study was $\mathrm{CaCO}_{3}$, or root-medium $\mathrm{pH}$, and we did not supply any chelated $\mathrm{Fe}$, whereas in previous studies, we applied different rates of $\mathrm{Fe}$ at a given $\mathrm{pH}$ using the synthetic chelate $\mathrm{Fe}(\mathrm{III})$ EDDHA [ferric ethylenediamine di (o-hydroxyphenylacetic) acid]. In the current experiments, although leaf total $\mathrm{Fe}$ content did decrease in the chlorotic leaves, active Fe decreased to a greater 

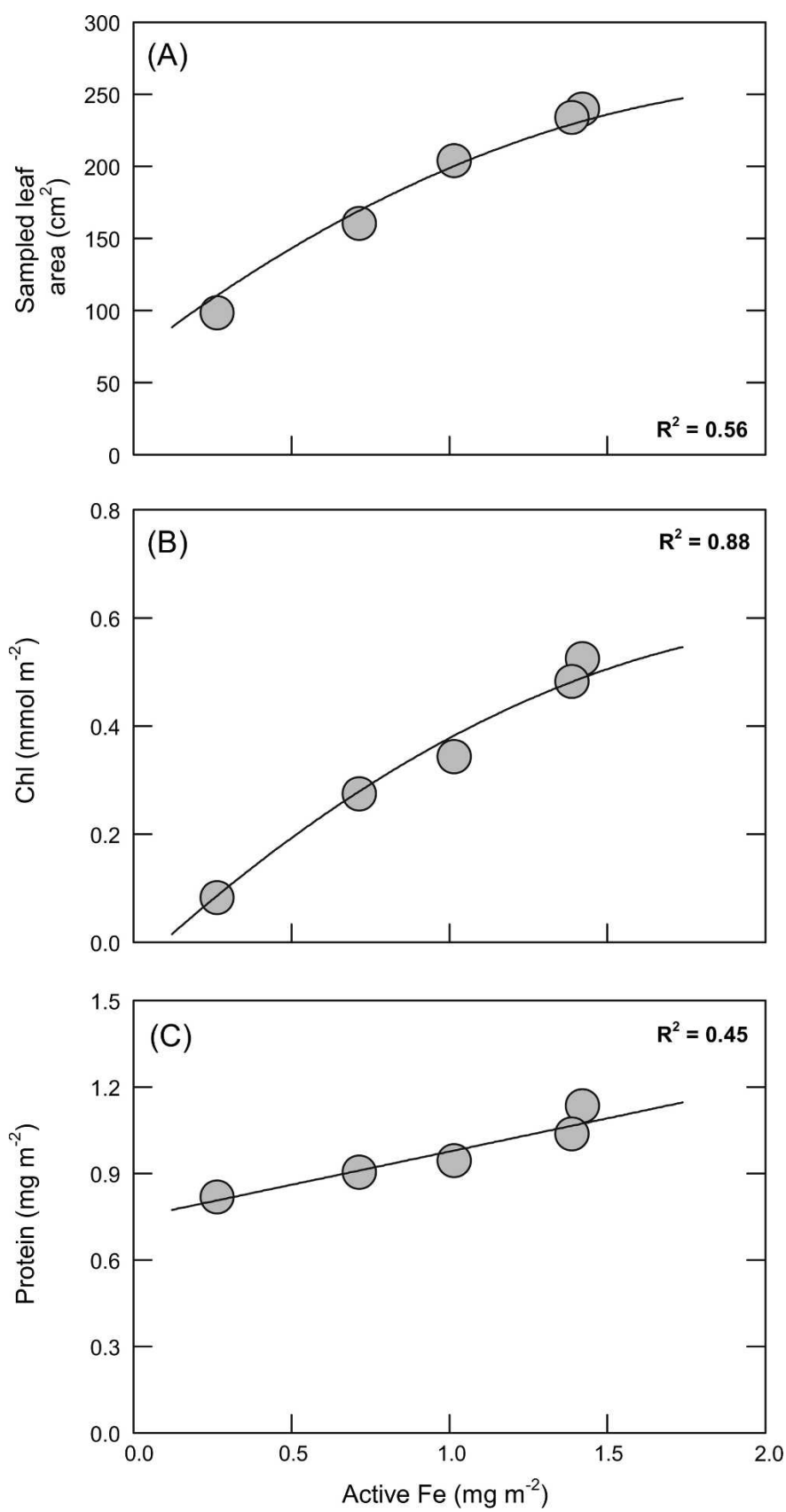

Fig. 3. (A) Area of recently matured leaf selected for biochemical analysis, (B) chlorophyll content of fresh leaves, and $(\mathbf{C})$ protein content in relation to foliar active Fe content of 'Concord' grapevines grown at five different $\mathrm{pHs}(\mathrm{n}=5)$. Regression equations for (A) $y=68.70+167.18 x-37.16 x^{2}\left(R^{2}=0.56, P<\right.$ $0.001),(\mathbf{B}) y=-0.05+0.54 x-0.11 x^{2}\left(R^{2}=0.88, P<0.001\right)$, and (C) $y=0.75+$ $0.23 x\left(R^{2}=0.45, P<0.001\right)$.

extent and was a better indicator of Fe nutritional status (Table 1; Fig. 2A-B).

Root FCR activity was increased in 'Concord' vines in response to high $\mathrm{pH}$-induced $\mathrm{Fe}$ deficiency, but there was not a corresponding upregulation of foliar FCR activity (Table 1). At low $\mathrm{pH}$, 'Concord' roots were able to extract enough $\mathrm{Fe}$ from the root medium to support healthy growth; however, a 10-fold increase in root FCR activity at high $\mathrm{pH}$ apparently did not compensate for decreased Fe solubility. Surprisingly, FCR activity in 'Concord' roots grown at high $\mathrm{pH}$ was greater than rates obtained for Fe-efficient grapevine and kiwifruit [Actinidia deliciosa (A.Chev.) C.F. Liang. \& A.R. Ferguson] cultivars (Bavaresco et al., 1991; Ksouri et al., 2006; Rombolà et al., 2002). Ksouri et al. (2006) found that root FCR activity did not increase in chlorosis-susceptible 'Balta4' grapevines in response to bicarbonate-induced chlorosis, but did increase three- to fourfold in the chlorosis-resistant 'Khamri'. From comparison with these data, it appears that $V$. labruscana roots are Fe-efficient. Yet leaves from vines grown at high $\mathrm{pH}$ were severely chlorotic (Table 1) and this alone confirms that $V$. labruscana is not Fe-efficient. Our results for root and shoot FCR activity in 'Concord' grapevines suggest that limeinduced chlorosis may be the result of impaired Fe assimilation from decreased foliar FCR activity rather than from decreased Fe uptake at the root level. Further use of the leaf disc assay is needed to compare FCR activity between chlorosis-susceptible and chlorosis-resistant grapevine genotypes.

In addition to reducing total dry weight and leaf area (Fig. $1 \mathrm{~A}-\mathrm{B}$ ), a decrease in active $\mathrm{Fe}$ corresponded to smaller leaves that contained less $\mathrm{Chl}$ and protein (Fig. 3A-C). The decrease in active $\mathrm{Fe}$ also resulted in a curvilinear decrease in $\mathrm{CO}_{2}$ assimilation, $g_{\mathrm{S}}$, and PSII quantum efficiency and a curvilinear increase in the calculated intercellular $\mathrm{CO}_{2}$ concentration (Fig. $4 \mathrm{~A}-\mathrm{D}$ ). These trends are similar to those observed in previous experiments in which vines were treated with different rates of Fe(III)-EDDHA (Chen et al., 2004; Smith and Cheng, 2005, 2006), indicating that physiological responses to Fe deficiency from a lack of applied Fe (so-called "direct" or "true" Fe deficiency) are similar to those resulting from lime-induced (or indirect) Fe deficiency.

The decrease in night respiration, from $-1.05 \mu \mathrm{mol} \cdot \mathrm{m}^{-2} \cdot \mathrm{s}^{-1}$ at the highest active Fe content to $-0.72 \mu \mathrm{mol} \cdot \mathrm{m}^{-2} \cdot \mathrm{s}^{-1}$ at the lowest active Fe content (Fig. 4F), contrasts with most of the previous reports, which indicate that dark respiration is unaffected by Fe deficiency (Morales et al., 1998; Pushnik and Miller, 1989; Terry, 1983). Considering that $\mathrm{Fe}$ is a cofactor for aconitase (conversion of citrate to isocitrate) and is a key component of the mitochondrial electron transfer chain (Fe-S centers in complexes I, II, and III; heme prosthetic groups in cytochromes), it seems remarkable that Fe deficiency would not significantly impact respiration rates.

Pascal and Douce (1993) did find that Fe limitation decreased the maximum $\mathrm{O}_{2}$ consumption in sycamore cells (Acer pseudoplatanus L.), and they concluded that this was most likely from a decrease in the formation of $\mathrm{Fe}-\mathrm{S}$ centers in complex II (succinate:ubiquinone oxidoreductase). It is possible that nonphosphorylating bypasses such as rotenone-insensitive $\mathrm{NAD}(\mathrm{P}) \mathrm{H}$ dehydrogenase and alternative oxidase may play a greater role in mitochondrial electron transport under $\mathrm{Fe}$ deficiency. Although the function of the alternative oxidase (AOX) is not well understood, it has been shown to increase under nutrient stress, and when the rate of the tricarboxylic acid (TCA) cycle decreases (citrate and pyruvate activate AOX) (Moore et al., 2002; Siedow and Day, 2000). Electron flow through these alternative routes may help maintain (or increase) respiratory rates when the cytochrome pathway is inhibited or when respiratory substrates accumulate (Moore et al., 2002; Siedow and Day, 2000).

In addition, Pascal and Douce (1993) measured a 50\% decrease in mitochondrial aconitase activity under $\mathrm{Fe}$ deficiency and found that this corresponded to impaired citrate oxidation. Early on, Bacon et al. (1961) proposed that $\mathrm{Fe}$ 

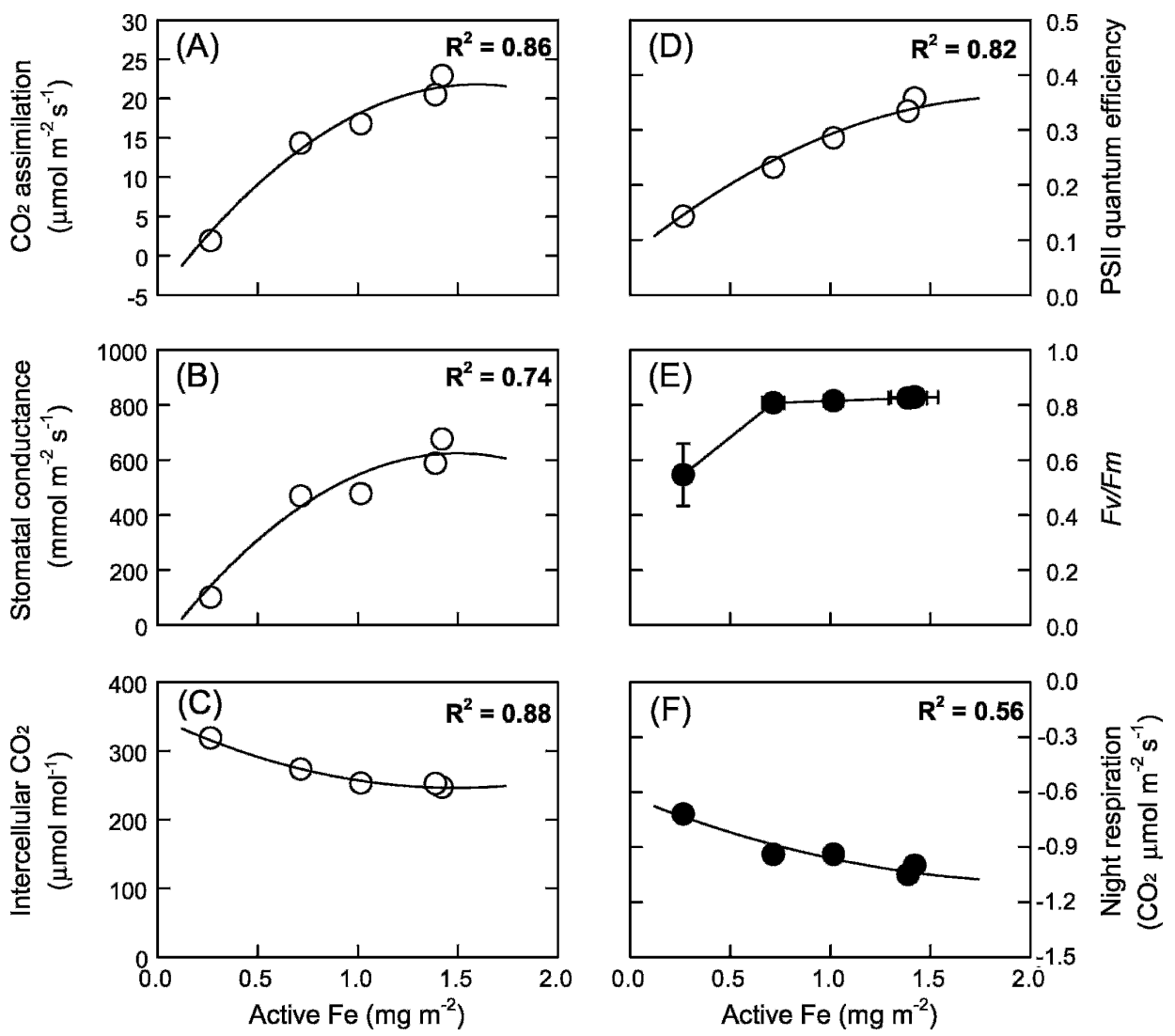

Fig. 4. (A) $\mathrm{CO}_{2}$ assimilation rate, $(\mathbf{B}) g_{\mathrm{S}},(\mathbf{C})$ calculated intercellular $\mathrm{CO}_{2}$ concentration, and (D) PSII quantum efficiency of leaves sampled at noon, and $(\mathbf{E})$ maximum photochemical efficiency $\left(F_{v} / F_{m}\right)$ and $(\mathbf{F})$ respiration rate of leaves sampled at midnight $(\mathrm{n}=5)$ in relation to foliar active Fe content of 'Concord' grapevines grown at five different $\mathrm{pHs}$. Regression equations for $(\mathbf{A}) y=-5.20+33.81 x-10.58 x^{2}\left(R^{2}=0.86, P<\right.$ $0.001),(\mathbf{B}) y=-87.23+948.67 x-316.48 x^{2}\left(R^{2}=0.74, P<0.001\right),(\mathbf{C}) y=348.25-137.15 x+46.02 x^{2}\left(R^{2}=\right.$ $0.88, P<0.001)$, (D) $y=0.07+0.29 x-0.08 x^{2}\left(R^{2}=0.82, P<0.001\right)$, and (F) $y=-0.62-0.44 x+0.10 x^{2}\left(R^{2}=\right.$ $0.56, P<0.001)$. Statistical significance for $(\mathbf{E})$ was determined by analysis of variance $(P<0.001)$; data are means $\pm \mathrm{SE}$

deficiency would decrease aconitase activity and result in citrate accumulation, yet recently there has been mixed support for this hypothesis (de Vos et al., 1986; López-Millàn et al., 2001a; McCluskey et al., 2004; Pich and Scholz, 1993). In fact, López-Millàn et al. (2001a) measured a 1.7-fold increase in aconitase activity in Fe-deficient sugar beet (Beta vulgaris L.) leaves. We found a strong, linear relationship between active Fe and aconitase activity (Fig. 3B), and leaves with low active Fe had three- to fourfold lower rates of aconitase activity compared with leaves with the highest active Fe. We were not able to obtain linear slopes for aconitase using citrate as a substrate and measuring either cis-aconitate formation at $240 \mathrm{~nm}$ or $\mathrm{NADP}^{+}$reduction at $340 \mathrm{~nm}$ (coupled with IDH) as described by de Vos et al. (1986). Nor were we able to successfully measure activity in the reverse direction using isocitrate as a substrate (Bacon et al., 1961). We were able to obtain linear slopes using $c i s$-aconitate as substrate and measuring $\mathrm{NADP}^{+}$ reduction at $340 \mathrm{~nm}$ in a coupled assay with IDH as described by Jenner et al. (2001). We are unsure why stable measurements could only be made using cis-aconitate, but suggest that aconitase determination in relation to Fe deficiency warrants further investigation.

A decrease in aconitase activity in response to lower active $\mathrm{Fe}$ corresponded to an increase in citrate content; however, there was no difference in foliar citrate content between day and night, although aconitase activity was higher in leaves sampled at night (Figs. 5B and $6 \mathrm{E})$. The lack of a relationship between the diurnal changes in enzyme and substrate is unclear, but it is reasonable to assume that the accumulation of citrate in Fe-deficient leaves was the result of lower leaf aconitase activity. Citrate concentration in the xylem sap decreased as soil $\mathrm{pH}$ increased (and leaf active $\mathrm{Fe}$ decreased); thus, loading of citrate in the xylem sap from the roots most likely did not contribute to high levels of citrate in the leaves in contrast to the proposal by López-Millàn et al. (2001a).

In recent reviews, both Schmidt (1999) and Abadía et al. (2002) concluded that organic acid accumulation in Fe-deficient tissues was primarily from the increased activity of PEP carboxylase (particularly at the root level) and not related to lower aconitase activity. We found that foliar PEP carboxylase activity did increase as active $\mathrm{Fe}$ decreased (Fig. 5I); however, malate content did not follow the same trend (Fig. 6D). Both citrate content and PEP carboxylase activity did increase as active Fe decreased, but with the exception of aconitase, the activity of all of the other enzymes we measured also increased under $\mathrm{Fe}$ deficiency (Fig. 5A-J). Therefore, we agree with Bacon et al. (1961) and Pascal and Douce (1993) that Fe deficiency decreases aconitase activity in the leaves and that the accumulation of foliar citrate is the result of impaired citrate oxidation in the TCA cycle.

We suggest that the increased activity of the other enzymes we measured is a response to lower aconitase activity, helps funnel carbon into the mitochondria, and increases the capacity to reduce pyridine nucleotides as the TCA cycle slows. In C3 plants, PEP carboxylase activity, and the import of malate and OAA into the mitochondria, functions primarily in an anaplerotic role to replenish TCA cycle intermediates exported for ammonia assimilation and amino acid synthesis (Plaxton, 1996; Siedow and Day, 2000). In addition, the observed increase of NADP-malic enzyme, NADP-IDH, and G6PDH activity under Fe deficiency would increase the NADPH needed for biosynthetic reaction. It is also possible that the increase in G6PDH activity (and flux through the pentose-phosphate pathway) may not only provide NADPH, but may also bypass phosphofructokinase (PFK) and supply triose phosphates for conversion to PEP when PFK is inhibited by citrate (Givan, 1999).

In this study, we found that PGA, G6P, and F6P decreased as active $\mathrm{Fe}$ decreased, and the difference between day and night content of PGA and G6P also decreased, indicating that Fedeficient leaves are carbon-limited. Interestingly, in previous 

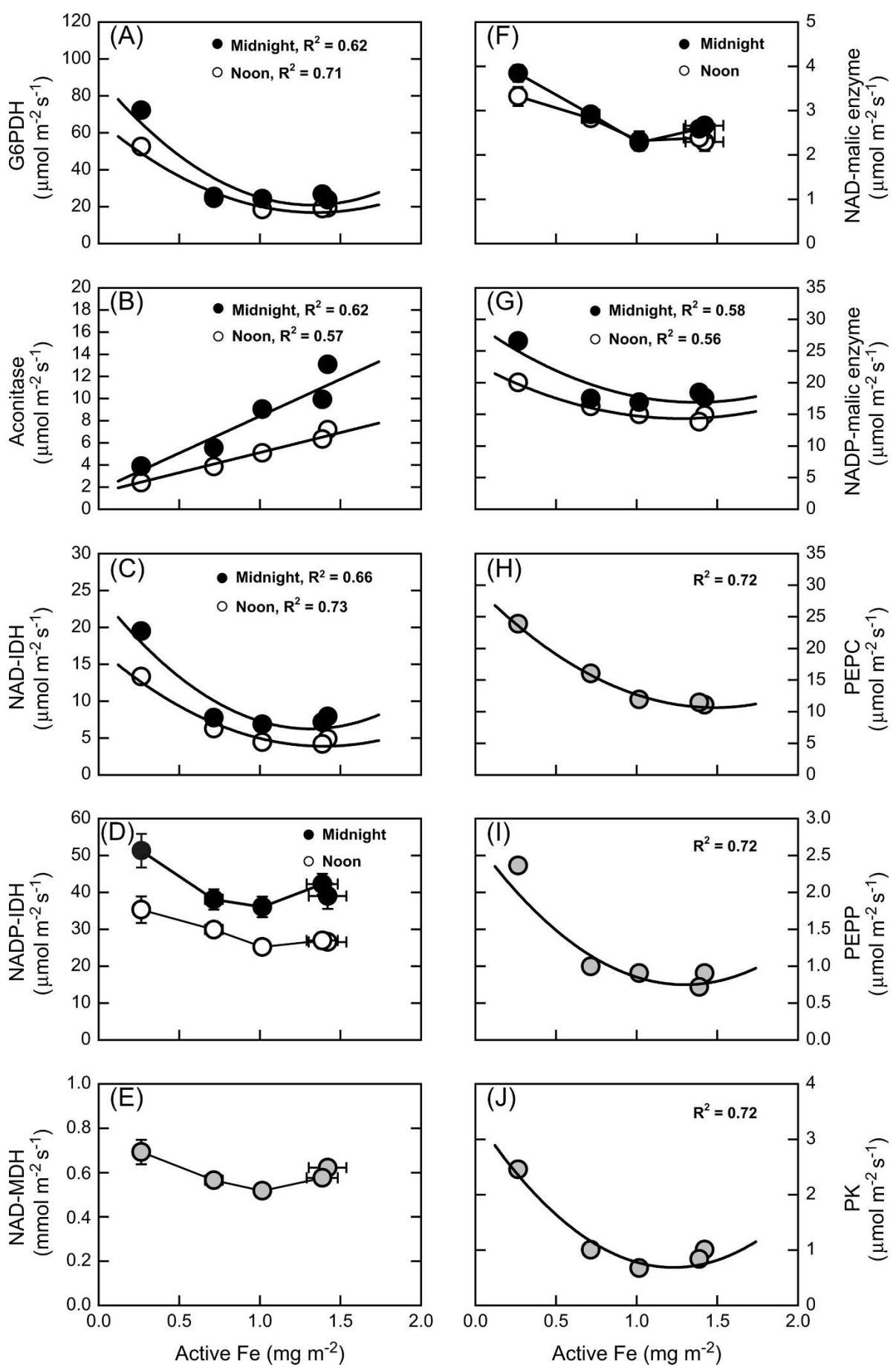

Fig. 5. Activity of (A) glucose-6-phosphate dehydrogenase (G6PDH), (B) aconitase, (C) NAD-isocitrate dehydrogenase (NAD-IDH), (D) NADP-isocitrate dehydrogenase (NADP-IDH), (E) NAD-malate dehydrogenase (NAD-MDH), (F) NAD-malic enzyme, (G) NADP-malic enzyme, (H) phosphoenolpyruvate carboxylase (PEPC), (I) phosphoenolpyruvate phosphatase (PEPP), and (J) pyruvate kinase (PK) in relation to foliar active Fe content of 'Concord' grapevines grown at five different $\mathrm{pHs}(\mathrm{n}=5)$. Open circles in the figures reflect data collected at noon, and black circles represent data collected at midnight. In situations in which time of day was not significant $(P>0.05)$ using analysis of variance, treatments were grouped together and are indicated by gray circles $(\mathrm{n}=10)$. Regression equations for $(\mathbf{A})$ noon: $y=66.55-73.94 x+$ $27.45 x^{2}\left(R^{2}=0.71, P<0.001\right)$, midnight: $y=90.15-104.75 x+39.57 x^{2}\left(R^{2}=0.62, P<0.001\right)$; (B) noon: $y=$ $1.49+3.62 x\left(R^{2}=0.57, P<0.001\right)$, midnight: $y=1.72+6.67 x\left(R^{2}=0.62, P<0.001\right) ;(\mathbf{C})$ noon: $y=17.10$ $18.89 x+6.76 x^{2}\left(R^{2}=0.73, P<0.001\right)$, midnight: $y=90.15-104.75 x+39.57 x^{2}\left(R^{2}=0.66, P<0.001\right) ;(\mathbf{G})$ noon: $y=22.97-13.52 x+5.29 x^{2}\left(R^{2}=0.56, P<0.001\right)$, midnight: $y=29.32-18.14 x+6.62 x^{2}\left(R^{2}=0.58, P<\right.$ $0.001)$; (H) $y=29.80-25.82 x+8.70 x^{2}\left(R^{2}=0.72, P<0.001\right)$; (I) $y=2.70-3.00 x+1.16 x^{2}\left(R^{2}=0.72, P<0.001\right)$; (J) $y=3.39-4.41 x+1.79 x^{2}\left(R^{2}=0.72, P<0.001\right)$. Statistical significance for (D) NADP-IDH $(P<0.001)$, (E) NAD-MDH $(P<0.05)$, and $(\mathbf{F})$ NADP-malic enzyme $(P<0.001)$ was determined by analysis of variance; data are means \pm SE. work with 'Concord' grapevines grown with different rates of $\mathrm{Fe}$ EDDHA, only PGA content decreased as active $\mathrm{Fe}$ decreased, whereas G6P and F6P content did not change (Chen et al., 2004). Espen et al. (2000) found elevated G6P and F6P levels in Fedeficient cucumber (Cucumis sativus L.) roots, but there are little data for foliar hexose phosphate content in relation to Fe nutrition. Malate content in the leaves followed a similar pattern to the concentration in the xylem sap, and it is possible that root export of malate contributed to foliar malate levels more than PEP carboxylase activity in the leaves (Figs. 6D and 7D).

Contrary to what we hypothesized, xylem sap $\mathrm{pH}$ did not change in response to $\mathrm{CaCO}_{3}$ application (Fig. $7 \mathrm{~A}$ ). It is possible that root PEP carboxylase may have fixed any $\mathrm{HCO}_{3}^{-}$taken up by the roots (and regulated the $\mathrm{pH}$ ), but citrate and malate content in the xylem sap does not reflect this assumption. It is interesting that citrate concentration in the xylem exudate was much lower than malate, a trend that was also similar in the leaves (citrate was an order of magnitude lower than malate), because Fe efficiency is often associated with high citrate levels (Brown and Ambler, 1970; Fournier et al., 1992). We could not find data to compare foliar citrate levels in Vitis spp.; however, Ollat et al. (2003) recently demonstrated the link between Fe efficiency and citrate in grapevine roots. When grown in $\mathrm{Fe}-$ deficient $(0.5 \mu \mathrm{M}$ Fe-EDTA $)$ vs. Fesufficient $(10 \mu \mathrm{M}$ Fe-EDTA) conditions, citrate levels in root tips of high $\mathrm{pH}$-tolerant Vitis berlandieri Planch. $\times V$. vinifera 'Fercal' were 9.8 and $1.0 \mathrm{mg} \cdot \mathrm{g}^{-1}$, respectively, whereas in the high $\mathrm{pH}$-susceptible Vitis rupestris Scheele $\times$ Vitis riparia Michx. '10114', citrate was 0.7 and $0.4 \mathrm{mg} \cdot \mathrm{g}^{-1}$, respectively. In the $\mathrm{Fe}$-sufficient sugar beet leaves, malate and citrate were 0.9 and $0.8 \mathrm{mmol} \cdot \mathrm{m}^{-2}$ and increased to 6.1 and $9.9 \mathrm{mmol} \cdot \mathrm{m}^{-2}$ under $\mathrm{Fe}$ deficiency, respectively (López-Millàn et al., 2001a). Thus, it is possible that lower citrate levels in 'Concord' vines are related to its susceptibility to lime-induced chlorosis.

In conclusion, root FCR activity is enhanced, whereas leaf FCR activity 

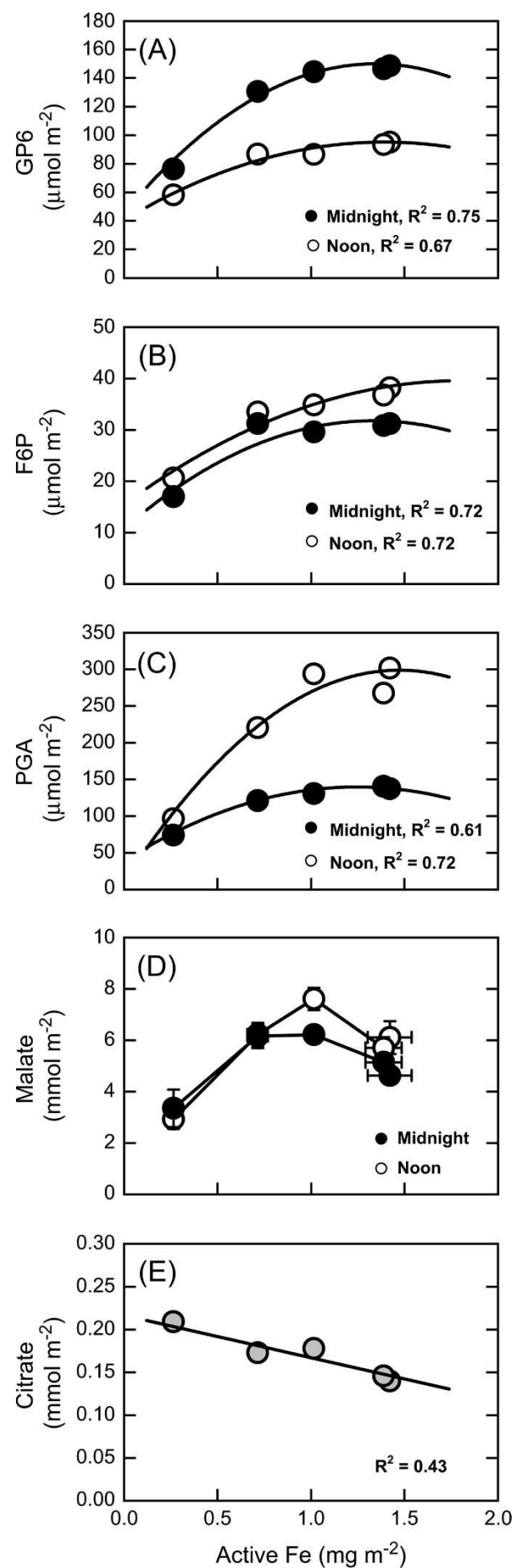

Fig. 6. (A) Glucose 6-phosphate (G6P), (B) fructose 6-phosphate (F6P), (C) 3-phosphoglycerate (PGA), (D) malate, and (E) citrate content in relation to active Fe content in recently matured leaves of 'Concord' grapevines grown at five different $\mathrm{pHs}(\mathrm{n}=5)$. Open circles in the figures reflect data collected at noon, and black circles represent data collected at midnight. In situations in which time of day was not significant $(P>0.05)$ using analysis of variance, treatments were grouped together and are indicated by gray circles $(\mathrm{n}=10)$. Regression equations for (A) noon: $y=40.54+78.51 x-28.21 x^{2}\left(R^{2}=0.67\right.$, $P<0.001)$, midnight: $y=45.56+155.59 x-57.95 x^{2}\left(R^{2}=0.75, P<0.001\right)$; (B) noon: $y=15.47+26.72 x-7.41 x^{2}\left(R^{2}=0.72, P<0.001\right)$, midnight: $y=10.76+$ $31.50 x-11.81 x^{2}\left(R^{2}=0.72, P<0.001\right)$; $(\mathbf{C})$ noon: $y=10.31+391.87 x-$ $133.07 x^{2}\left(R^{2}=0.72, P<0.001\right)$, midnight: $y=38.62+162.11 x-65.00 x^{2}\left(R^{2}=\right.$ $0.61, P<0.001)$, (E) $y=0.22-0.05 x\left(R^{2}=0.43, P<0.001\right)$. Statistical significance for $(\mathbf{D})$ malate $(P<0.001)$ was determined by analysis of variance; data are means $\pm \mathrm{SE}$.
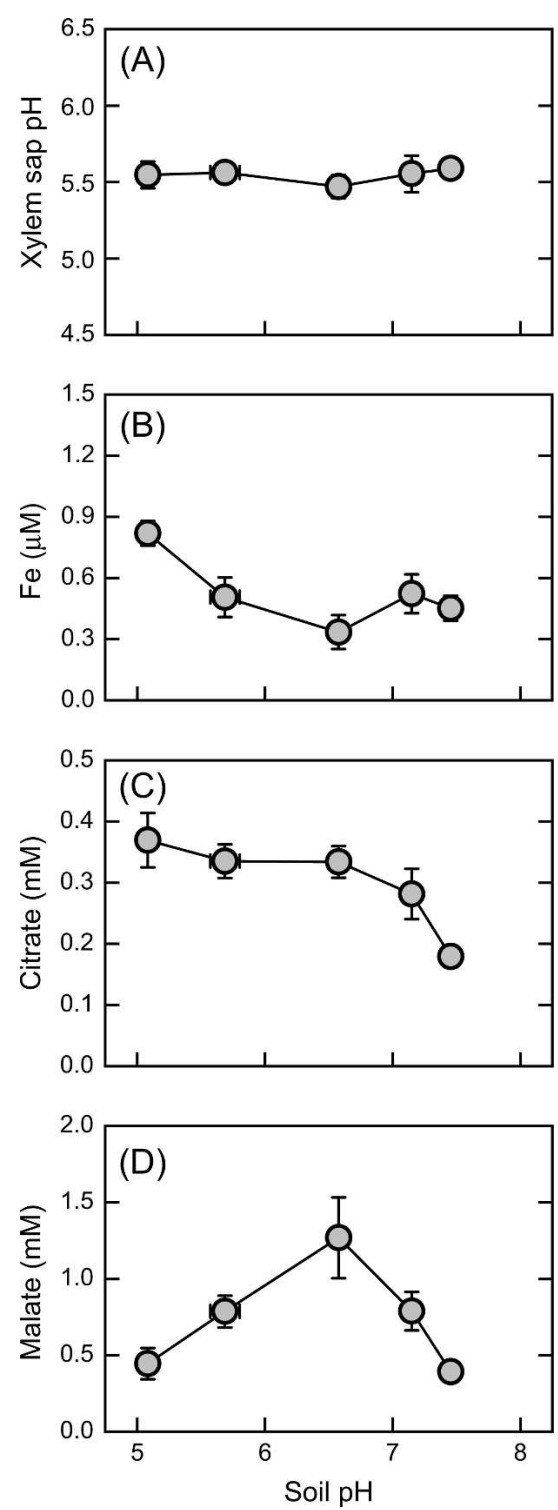

Fig. 7. (A) Xylem sap $\mathrm{pH}(P=$ not significant) and the concentration of (B) $\mathrm{Fe}$ $(P<0.05),(\mathbf{C})$ citrate $(P<0.05)$, and $(\mathbf{D})$ malate $(P<0.05)$ in the xylem sap expressed from $30-\mathrm{cm}$ shoot tips of 'Concord' grapevines grown at five different $\mathrm{pHs}$. Statistical significance was determined by analysis of variance; data are means $\pm \operatorname{SE}(n=5)$.

is decreased under high $\mathrm{pH}$-induced Fe deficiency in 'Concord' vines. Xylem sap $\mathrm{pH}$ did not change and does not appear to be related to the observed soil $\mathrm{pH}$ effects. The decreased leaf aconitase activity under Fe deficiency is the most likely cause of the increase in citrate levels. Greater activity of the other glycolytic and TCA enzymes under Fe deficiency may help to funnel carbon into the mitochondria and enhance $\mathrm{NAD}(\mathrm{P})$ reduction. Compared with other species, Concord vines have much lower levels of citrate (and the citrate:malate ratios) in the xylem exudate and leaves, which may be linked to $\mathrm{Fe}$ inefficiency. Reciprocal grafting experiments between $V$. labruscana and an Fe-efficient genotype will help determine whether the limiting factor in $\mathrm{Fe}$ assimilation at high $\mathrm{pH}$ is primarily at the root or leaf level. 


\section{Literature Cited}

Abadía, J., A.F. López-Millán, A. Rombolà, and A. Abadía. 2002. Organic acids and Fe deficiency: A review. Plant Soil 241:75-86.

Arnon, D.I. 1949. Copper enzymes in isolated chloroplasts-Polyphenoloxidase in Beta vulgaris. Plant Physiol. 24:1-15.

Bacon, J.S., P.C. DeKock, and M.J. Palmer. 1961. Aconitase levels in leaves of iron-deficient mustard plants (Sinapis alba). Biochem. J. 80:64-70.

Bavaresco, L., M. Fregoni, and P. Fraschini. 1991. Investigations on iron uptake and reduction by excised roots of different grapevine rootstocks and a Vitis vinifera cultivar. Plant Soil 130:109-114.

Bavaresco, L., E. Giachino, and S. Pezzutto. 2003. Grapevine rootstock effects on lime-induced chlorosis, nutrient uptake, and source-sink relationships. J. Plant Nutr. 26:1451-1465.

Bradford, M.M. 1976. Rapid and sensitive method for quantitation of microgram quantities of protein utilizing principle of protein-dye binding. Anal. Biochem. 72:248-254.

Brancadoro, L., G. Rabotti, A. Scienza, and G. Zocchi. 1995. Mechanisms of Fe-efficiency in roots of Vitis spp. in response to iron-deficiency stress. Plant Soil 171:229-234.

Brown, J.C. and J.E. Ambler. 1970. Further characterization of iron uptake in 2 genotypes of corn. Soil Sci. Soc. Amer. Proc. 34:249.

Brüggemann, W., K. Maaskantel, and P.R. Moog. 1993. Iron uptake by leaf mesophyll-cells - The role of the plasma membrane-bound ferric-chelate reductase. Planta 190:151-155.

Chaney, R.L., J.C. Brown, and L.O. Tiffin. 1972. Obligatory reduction of ferric chelates in iron uptake by soybean. Plant Physiol. 50:208-213. Chen, L.-S., B.R. Smith, and L. Cheng. 2004. $\mathrm{CO}_{2}$ assimilation, photosynthetic enzymes, and carbohydrates of 'Concord' grape leaves in response to iron supply. J. Amer. Soc. Hort. Sci. 129: 738-744.

Chen, L.S. and L. Cheng. 2003. Both xanthophyll cycle-dependent thermal dissipation and the antioxidant system are up-regulated in grape (Vitis labrusca L. Cv. Concord) leaves in response to $\mathrm{N}$ limitation. J. Expt. Bot. 54:2165-2175.

Davenport, J.R. and R.G. Stevens. 2006. High soil moisture and low soil temperature are associated with chlorosis occurrence in Concord grape. HortScience 41:418-422.

Davies, D.D. 1986. The fine control of cytosolic pH. Physiol. Plant. 67:702-706.

de la Guardia, M.D. and E. Alcantara. 1996. Ferric chelate reduction by sunflower (Helianthus annuus L.) leaves: Influence of light, oxygen, iron-deficiency and leaf age. J. Expt. Bot. 47:669-675.

de Vos, C.R., H.J. Lubberding, and H.F. Bienfait. 1986. Rhizosphere acidification as a response to iron-deficiency in bean-plants. Plant Physiol. 81:842-846.

Espen, L., M. Dell'Orto, P. De Nisi, and G. Zocchi. 2000. Metabolic responses in cucumber (Cucumis sativus L.) roots under Fe-deficiency: A 31P-nuclear magnetic resonance in-vivo study. Planta 210:985992.

Felle, H. 1988. Short-term pH regulation in plants. Physiol. Plant. 74:583-591.

Fournier, J.M., E. Alcantara, and M.D. de la Guardia. 1992. Organicacid accumulation in roots of 2 sunflower lines with a different response to iron-deficiency. J. Plant Nutr. 15:1747-1755.

Genty, B., J.M. Briantais, and N.R. Baker. 1989. The relationship between the quantum yield of photosynthetic electron transport and quenching of chlorophyll fluorescence. Biochim. Biophys. Acta 990:87-92.

Gezgin, S. and F. Er. 2001. Relationship between total and active iron contents of leaves and observed chlorosis in vineyards in KonyaHadim-Alada region of turkey. Commun. Soil Sci. Plant Anal. 32:1513-1521.

Givan, C.V. 1999. Evolving concepts in plant glycolysis: Two centuries of progress. Biol. Rev. 74:277-309.

Gonzalez-Vallejo, E.B., F. Morales, L. Cistue, A. Abadía, and J. Abadía. 2000. Iron deficiency decreases the Fe(III)- chelate reducing activity of leaf protoplasts. Plant Physiol. 122:337-344.

Grotz, N. and M.L. Guerinot. 2002. Limiting nutrients: An old problem with new solutions? Curr. Opin. Plant Biol. 5:158-163.

Gruber, B. and H. Kosegarten. 2002. Depressed growth of nonchlorotic vine grown in calcareous soil is an iron deficiency symptom prior to leaf chlorosis. J. Plant Nutr. Soil Sci. 165:111117.

Jenner, H.L., B.M. Winning, A.H. Millar, K.L. Tomlinson, C.J. Leaver, and S.A. Hill. 2001. NAD malic enzyme and the control of carbohydrate metabolism in potato tubers. Plant Physiol. 126:1139-1149.

Jones, D.L. 1998. Organic acids in the rhizosphere-A critical review. Plant Soil 205:25-44.

Kosegarten, H., B. Hoffmann, and K. Mengel. 2001. The paramount influence of nitrate in increasing apoplastic $\mathrm{pH}$ of young sunflower leaves to induce Fe deficiency chlorosis, and the re-greening effect brought about by acidic foliar sprays. J. Plant Nutr. Soil Sci. 164:155-163.

Ksouri, R., S. M'rah, M. Gharsalli, and M. Lachaâl. 2006. Biochemical responses to true and bicarbonate-induced iron deficiency in grapevine genotypes. J. Plant Nutr. 29:305-315.

Landsberg, E.C. 1981. Organic-acid synthesis and release of hydrogen ions in response to $\mathrm{Fe}$ deficiency stress of monocotyledonous and dicotyledonous plant species. J. Plant Nutr. 3:579-591.

Larbi, A., F. Morales, A.F. López-Millàn, Y. Gogorcena, A. Abadía, P.R. Moog, and J. Abadía. 2001. Technical advance: Reduction of $\mathrm{Fe}(\mathrm{III})$-chelates by mesophyll leaf disks of sugar beet. Multicomponent origin and effects of Fe-deficiency. Plant Cell Physiol. 42:94-105.

Leegood, R.C. 1993. Carbon metabolism, p. 247-267. In: D.O. Hall, J.M.O. Scurlock, H.R. Bolhar-Nordenkampf, R.C. Leegood, and S.P. Long (eds.). Photosynthesis and production in a changing environment: A field and laboratory manual. Chapman \& Hall, London.

Lindsay, W.L. and A.P. Schwab. 1982. The chemistry of iron in soils and its availability to plants. J. Plant Nutr. 5:821-840.

López-Millàn, A.F., F. Morales, A. Abadía, and J. Abadía. 2001a. Changes induced by Fe deficiency and Fe resupply in the organic acid metabolism of sugar beet (Beta vulgaris) leaves. Physiol. Plant. 112:31-38.

López-Millàn, A.F., F. Morales, A. Abadía, and J. Abadía. 2001b. Iron deficiency-associated changes in the composition of the leaf apoplastic fluid from field-grown pear (Pyrus communis L.) trees. J. Expt. Bot. 52:1489-1498.

Lucena, J.J. 2000. Effects of bicarbonate, nitrate and other environmental factors on iron deficiency chlorosis. A review. J. Plant Nutr. 23:1591-1606.

Marschner, H., V. Römheld, and M. Kissel. 1986. Different strategies in higher-plants in mobilization and uptake of iron. J. Plant Nutr. 9:695-713.

McCluskey, J., L. Herdman, and K.R. Skene. 2004. Iron deficiency induces changes in metabolism of citrate in lateral roots and cluster roots of Lupinus albus. Physiol. Plant. 121:586-594.

Mengel, K., M.T. Breininger, and W. Bubl. 1984a. Bicarbonate, the most important factor inducing iron chlorosis in vine grapes on calcareous soil. Plant Soil 81:333-344.

Mengel, K., W. Bubl, and H.W. Scherer. 1984b. Iron distribution in vine leaves with bicarbonate induced chlorosis. J. Plant Nutr. 7:715724.

Moore, A.L., M.S. Albury, P.G. Crichton, and C. Affourtit. 2002. Function of the alternative oxidase: Is it still a scavenger? Trends Plant Sci. 7:478-481.

Morales, F., A. Abadía, and J. Abadía. 1998. Photosynthesis, quenching of chlorophyll fluorescence and thermal energy dissipation in iron-deficient sugar beet leaves. Aust. J. Plant Physiol. 25:403412.

Nikolic, M. and V. Römheld. 2002. Does high bicarbonate supply to roots change availability of iron in the leaf apoplast? Plant Soil 241:67-74. 
Nikolic, M. and V. Römheld. 2003. Nitrate does not result in iron inactivation in the apoplast of sunflower leaves. Plant Physiol. 132:1303-1314.

Ollat, N., W. Laborde, M. Neveux, P. Diakou-Verdin, C. Renaud, and A. Moing. 2003. Organic acid metabolism in roots of various grapevine (Vitis) rootstocks submitted to iron deficiency and bicarbonate nutrition. J. Plant Nutr. 26:2165-2176.

Oserkowsky, J. 1933. Quantitative relation between chlorophyll and iron in green and chlorotic pear leaves. Plant Physiol. 8:440-468.

Pascal, N. and R. Douce. 1993. Effect of iron-deficiency on the respiration of sycamore (Acer pseudoplatanus L.) cells. Plant Physiol. 103:1329-1338.

Passonneau, J.V. and O.H. Lowry. 1993. Enzymatic analysis: A practical guide. Humana Press, Totowa, NJ.

Pich, A. and G. Scholz. 1993. The relationship between the activity of various iron-containing and iron-free enzymes and the presence of nicotianamine in tomato seedlings. Physiol. Plant. 88:172178.

Plaxton, W.C. 1990. Glycolysis, p. 145-173. In: P.J. Lea (ed.). Methods in plant biochemistry. Academic Press, London.

Plaxton, W.C. 1996. The organization and regulation of plant glycolysis. Ann. Rev. Plant Physiol. Plant Mol. Biol. 47:185214.

Poonnachit, U. and R. Darnell. 2004. Effect of ammonium and nitrate on ferric chelate reductase and nitrate reductase in Vaccinium species. Ann. Bot. (Lond.) 93:399-405.

Pushnik, J.C. and G.W. Miller. 1989. Iron regulation of chloroplast photosynthetic function-mediation of PSI development. J. Plant Nutr. 12:407-421.

Rabotti, G., P. Denisi, and G. Zocchi. 1995. Metabolic implications in the biochemical responses to iron-deficiency in cucumber (Cucumis sativus L.) roots. Plant Physiol. 107:1195-1199.

Rombolà, A.D., W. Brüggemann, A.F. López-Millán, M. Tagliavini, J. Abadía, B. Marangoni, and P.R. Moog. 2002. Biochemical responses to iron deficiency in kiwifruit (Actinidia deliciosa). Tree Physiol. 22:869-875.

Rombolà, A.D., W. Brüggemann, M. Tagliavini, B. Marangoni, and P.R. Moog. 2000. Iron source affects iron reduction and re-greening of kiwifruit (Actinidia deliciosa) leaves. J. Plant Nutr. 23:17511765.
Römheld, V. and H. Marschner. 1981. Effect of Fe stress on utilization of Fe chelates by efficient and inefficient plant species. J. Plant Nutr. 3:551-560.

Römheld, V. and H. Marschner. 1983. Mechanism of iron uptake by peanut plants.1. FeIII reduction, chelate splitting, and release of phenolics. Plant Physiol. 71:949-954.

Schmidt, W. 1999. Mechanisms and regulation of reduction-based iron uptake in plants. New Phytol. 141:1-26.

Siedow, J.N. and D.A. Day. 2000. Respiration and photorespiration, p. 676-728. In: B.B. Buchanan, W. Gruissem, and R.L. Jones (eds.). Biochemistry \& molecular biology of plants. American Society of Plant Physiologists, Rockville, MD.

Smith, B.R. and L. Cheng. 2005. Photoprotective mechanisms of 'Concord' grape leaves in relation to iron supply. J. Amer. Soc. Hort. Sci. 130:331-340.

Smith, B.R. and L. Cheng. 2006. FeEDDHA alleviates chlorosis in 'Concord' grapevines grown at high $\mathrm{pH}$. HortScience 41:1498-1501.

Stitt, M., R.M. Lilley, R. Gerhardt, and H.W. Heldt. 1989. Metabolite levels in specific cells and subcellular compartments of plant-leaves. Methods Enzymol. 174:518-552.

Terry, N. 1983. Limiting factors in photosynthesis. 4. Iron stressmediated changes in light-harvesting and electron-transport capacity and its effects on photosynthesis in vivo.. Plant Physiol. 71:855-860.

Tiffin, L.O. 1970. Translocation of iron citrate and phosphorus in xylem exudate of soybean. Plant Physiol. 45:280-283.

van Kooten, O. and J.F.H. Snel. 1990. The use of chlorophyll fluorescence nomenclature in plant stress physiology. Photosynth. Res. 25:147-150.

Vert, G., N. Grotz, F. Dedaldechamp, F. Gaymard, M.L. Guerinot, J.F. Briat, and C. Curie. 2002. IRT1, an Arabidopsis transporter essential for iron uptake from the soil and for plant growth. Plant Cell 14:1223-1233.

von Wiren, N., S. Klair, S. Bansal, J.F. Briat, H. Khodr, T. Shioiri, R.A. Leigh, and R.C. Hider. 1999. Nicotianamine chelates both FeIII and FeII. Implications for metal transport in plants. Plant Physiol. 119:1107-1114.

Wegner, L.H. and U. Zimmermann. 2004. Bicarbonate-induced alkalinization of the xylem sap in intact maize seedlings as measured in situ with a novel xylem pH probe. Plant Physiol. 136:34693477 . 